\title{
An Analysis of Solid Waste Generation and Characterization in Thika Municipality of Kiambu County, Kenya
}

\author{
Mugo Ephantus, Kinyua Robert and Njogu Paul \\ Institute of Energy and Environmental Technology, Jomo Kenyatta University of Agriculture and Technology, \\ Nairobi 62000-00200, Kenya
}

\begin{abstract}
The rapid increase in population in Thika has led to increase in municipal solid waste generation, which has posed challenges in the waste disposal and management. This study was carried out to quantify and characterize the waste generated within Thika municipality. Six months data (between March 2014 and August 2014) of waste stream at the dumpsite was reviewed and analyzed. The survey indicated that $66.95 \% \pm 0.34 \%$ of the total waste dumped originated from the municipal council of Thika (MCT). It constitutes of domestic, commercial and institutional waste. $33.05 \%$ is industrial waste. Sixty eight percent (68\%) of the waste consisted primarily of four components: paper, plastic, organics and food. Food accounted for $15.51 \% \pm 0.95 \%$, paper $18.31 \% \pm$ $1.7 \%$, plastics $17.89 \% \pm 0.81 \%$ and organics other than food $16.51 \% \pm 1.01 \%$, respectively obtained at $95 \%$ confidence level. Each of the components has some level of recovery. Some of the reusable and recyclable materials were being recovered, food waste had the highest recovery rate of $23 \% \pm 1.7 \%$ and was used as animal feed, while plastic (soft plastic) $17 \% \pm 0.93 \%$ was sold to recyclers. Recovery of materials for recycling and composting was estimated at 10.21 tonnes or $11.35 \%$ of daily generation, leaving 76.44 tonnes per day that can be converted into useful energy. The study shows waste in this dumpsite can be exploited to by converting it to energy thus a good solution for waste management.
\end{abstract}

Key words: Municipal solid waste, municipal solid waste management, waste to energy, Thika municipality.

\section{Introduction}

The quantification of the solid waste generated within a municipality is critical in determination of appropriate methods of waste management within that municipality. This information can also be useful in assessing whether this waste is sufficient to put up a waste to energy conversion facility within the municipality. Knowledge of the elemental composition of Municipal Solid Waste (MSW) will also guide engineers and scientists of its utility as a fuel (based on its calorific value) and will also help in predicting the makeup of gaseous emissions after it is subjected to the energy conversion technologies such as gasification, incineration etc as well as of possible

\footnotetext{
Corresponding author: Mugo Ephantus, master, main research field: energy technology. E-mail:meetephantus@yahoo.com.
}

hazardous substances occurring in the ash [1]. Waste composition will provide information on the utility of the material for composting or for biological conversion into biogas fuel [2]. In addition, given that the majority of MSW in the Republic of Kenya is disposed off in designated dumpsites, knowledge of chemical composition can help in predicting leachate composition and necessary treatment options. The physical properties of MSW will indicate ease of transport, processing requirements, energy conversion characteristics, and a rough prediction of landfill lifetime if there is need to design landfills [3]. The information from the quantification and characterization of the waste will also help policy makers in putting up good waste management practices as practiced elsewhere in the world. 


\section{Materials and Methods}

\subsection{Area of Study}

This study was carried out in Thika municipality in Thika District of Kiambu County. The district lies between latitudes $3^{\circ} 53^{\prime}$ and $1^{\circ} 45^{\prime}$ south of Equator and longitudes $36^{\circ} 35^{\prime}$ and $37^{\circ} 25^{\prime}$ east. Kang'oki dumpsite is the major dumpsite in the municipality where this study was carried out. The location of the study area is shown in Fig. 1.

\subsection{Data Collection}

Site-specific study methodology was used, where sampling, sorting, and weighing the individual components of the waste stream was done. This methodology is useful in defining a local waste stream [4], samples were collected from March up to August 2014 from the dumpsite as were dumped from different sources which are coded from $\mathrm{C} 1$ up to $\mathrm{C} 8$, sorted, weighed and recorded. Direct sampling was used to obtain information about MSW composition. The direct sampling method involved physically sampling and sorting MSW at the dumpsite. Although MSW can be extremely heterogeneous, direct sampling is one of the more accurate characterization methods [5]. In order to make accurate judgments as to composition, sorting and analysis were conducted in several randomly selected locations within the dumpsite. Waste sampling from single-and multi-family homes, commercial establishments (restaurants and businesses), and institutions (schools, hospitals) is encouraged, as it creates local variations [6]. This was easily achieved since the samples were obtained directly from the Lorries as they offloaded the waste at the dumpsite. The waste was collected and piled together then the quartering method was used to obtain the secondary sample which was weighed. The quartering method is illustrated in the Fig. 2.

In addition, quantities of MSW components such as food waste, papers, plastics and yard trimmings etc were characterized to determine the composition of

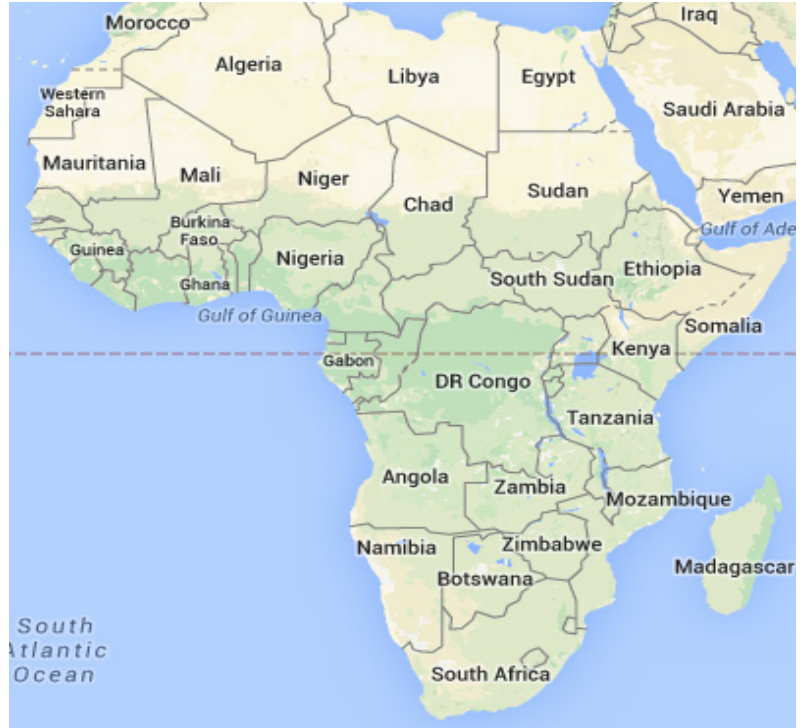

(a)

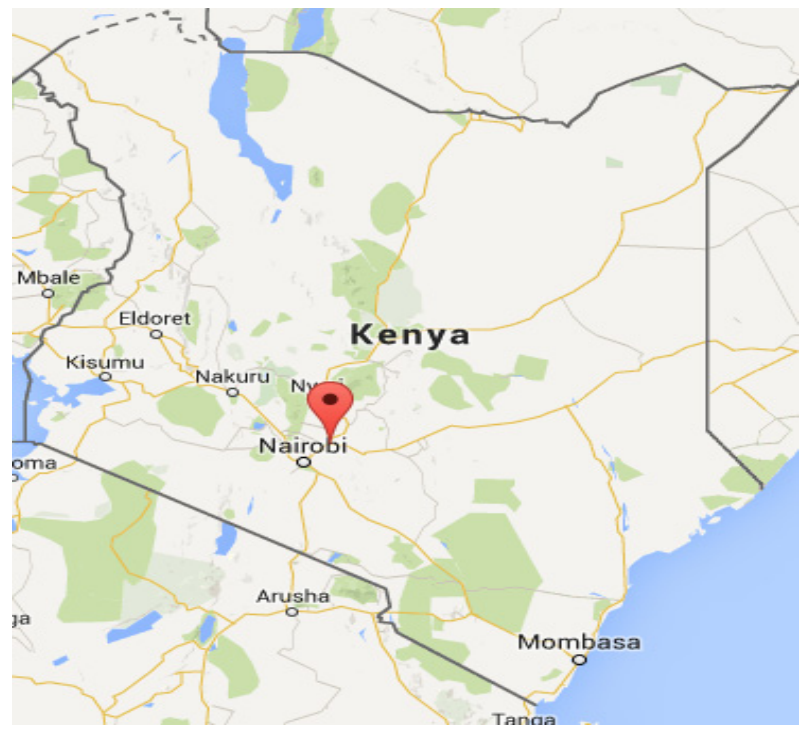

(b)

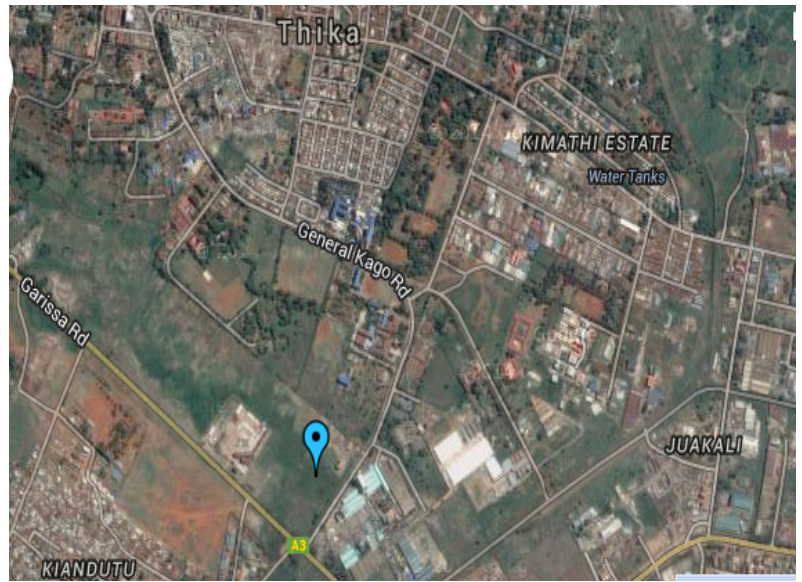

(c)

Fig. 1 (a): Map of Africa continent; (b): Map of Kenya; (c): Thika municipality in Kiambu County, Kenya. 

Municipality of Kiambu County, Kenya

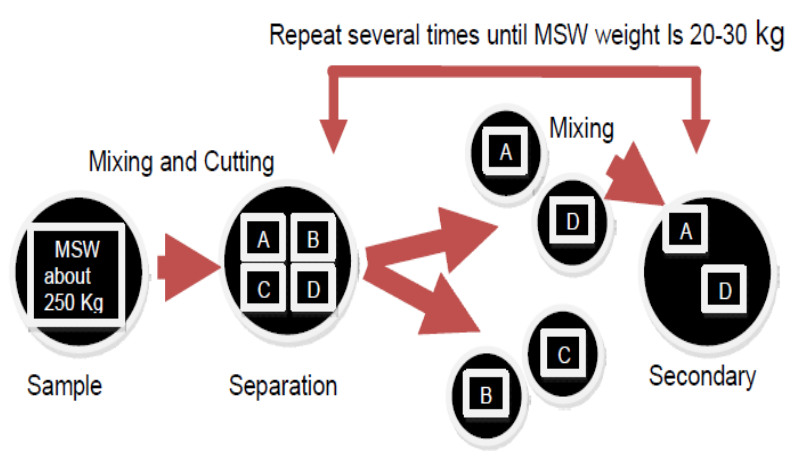

Fig. 2 General flow chart of quartering method [2].

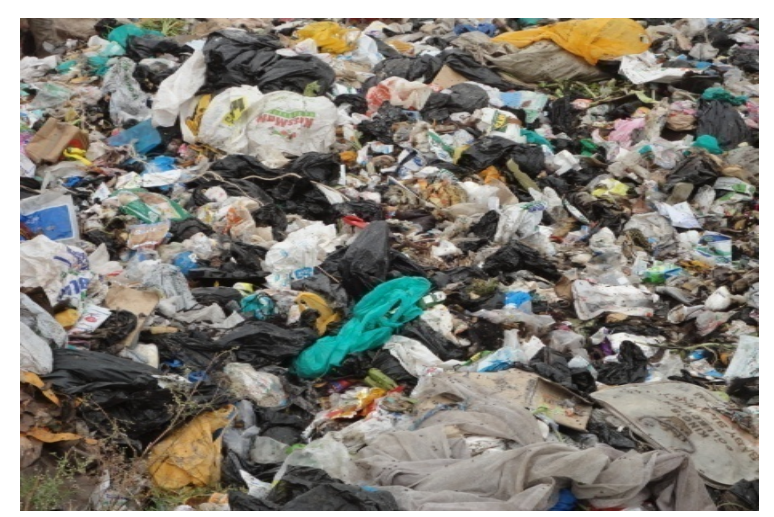

(a)

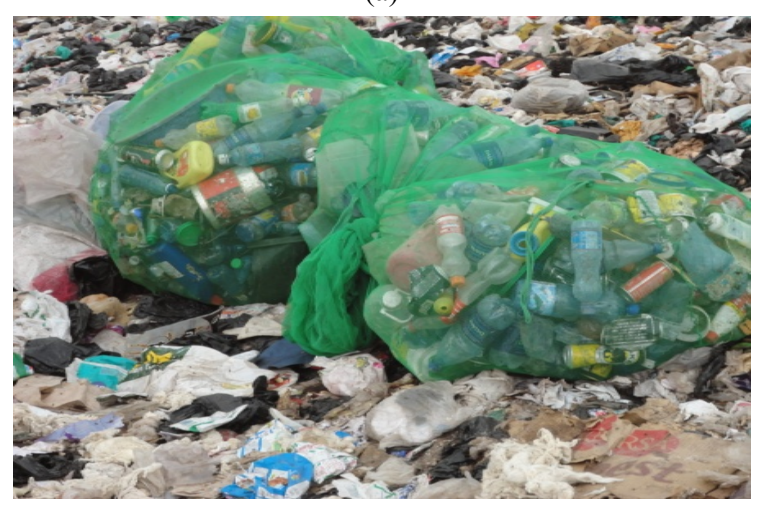

(b)

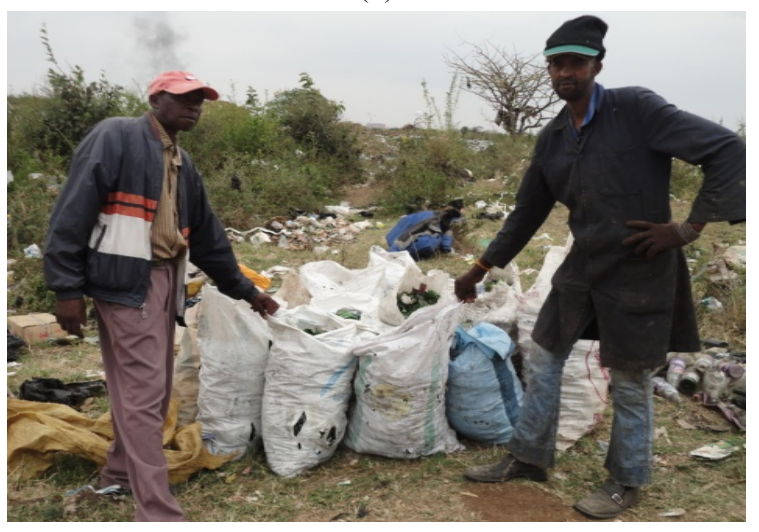

(c)

Fig. 3 (a) Mixed waste; (b) Separated plastic bottles; (c) Sorted waste ready for weighing. the waste at the dumpsite. After the characterization of the waste, elemental composition was determined.

\subsection{Data Analysis}

Data collected was analyzed using Excel spreadsheet and results presented in the tabular and graphical form. The data for each month was analyzed per week to determine the average weekly waste generation and its corresponding percentage proportion. The waste was also tabulated per source which also has the corresponding percentage contribution to the total waste. The results of the average weekly waste generation for the six months were used to calculate the average waste generation per week which was then used to project the annual waste generation and to approximate the daily waste generation. Considering the waste generation by source percentages the waste dumped to the dumpsite by municipal council of Thika was determined which was then used to determine the per capita waste generation based on the population of people living in Thika Municipality.

\section{Results and Discussion}

\subsection{Quantification of Waste in Thika Municipality}

The average waste generated in these six months formed a representative sample of the waste generated per month. On average $608.25 \pm 11$ tonnes/week are generated which is approximately 31,629 tonnes/year. This translates to approximately 86.15 tonnes/day of municipal solid waste generation. $66.95 \% \pm 0.34 \%$ of this waste comes from the MCT which constituted approximately 57.68 tonnes per day, with a per capita waste generation of $0.412 \mathrm{Kg}$ per person per day.

Table 2 shows on average $66.95 \% \pm 0.34 \%$ of the total waste dumped at the Kang'oki dumpsite constitutes the waste collected by the defunct municipal council of Thika (MCT) now under Thika Sub County. This waste constitutes domestic, commercial and institutional waste.

The remaining 33.05\% constitute the industrial waste from various industries in Thika. Out of the 
Table 1 Summary of the average weekly waste generation by source for the six months at $95 \%$ confidence level.

\begin{tabular}{llllllll}
\hline Source (coded) & $\begin{array}{l}\text { Av/week } \\
\text { March }\end{array}$ & $\begin{array}{l}\text { Av/week } \\
\text { April }\end{array}$ & $\begin{array}{l}\text { Av/week } \\
\text { May }\end{array}$ & $\begin{array}{l}\text { Av/week } \\
\text { June }\end{array}$ & $\begin{array}{l}\text { Av/week } \\
\text { July }\end{array}$ & $\begin{array}{l}\text { Av/week } \\
\text { August }\end{array}$ & Average \\
\hline MCT & 398.5 & 400 & 398.5 & 406 & 411.5 & 414.5 & $404.8 \pm 5$ \\
C1 & 33.25 & 31.5 & 34 & 40.25 & 41 & 38.75 & $36.5 \pm 5.1$ \\
C2 & 24.5 & 28 & 34.25 & 29.75 & 33.25 & 42 & $32 \pm 5.2$ \\
C3 & 32 & 32 & 32 & 29.75 & 32 & 33.5 & $31.9 \pm 5$ \\
C4 & 27 & 29.75 & 37.25 & 33 & 28 & 26.25 & $30.2 \pm 3.4$ \\
C5 & 10.5 & 8.75 & 5.25 & 5.25 & 7 & 12.25 & $8.2 \pm 2$ \\
C6 & 26.25 & 24.5 & 21 & 26.25 & 15.75 & 17.5 & $21.9 \pm 4$ \\
C7 & 7 & 7 & 5.25 & 5.25 & 5.25 & 15.75 & $7.6 \pm 4.3$ \\
C8 & 7 & 8.75 & 8.75 & 7 & 7 & 3.5 & $8.5 \pm 2$ \\
Other companies & 26.25 & 28 & 26.25 & 24.5 & 31.5 & 12.25 & $26.8 \pm 2$ \\
TOTAL & 592.25 & 598.25 & 602.25 & 607 & 612.25 & 616.25 & $608.25 \pm 11$ \\
\hline
\end{tabular}

Table 2 Summary of the waste generation by source for six months at $95 \%$ confidence level.

\begin{tabular}{llllllll}
\hline Source (coded) & $\begin{array}{l}\text { \%/Week } \\
\text { March }\end{array}$ & $\begin{array}{l}\text { \%/Week } \\
\text { April }\end{array}$ & $\begin{array}{l}\text { \%/week } \\
\text { May }\end{array}$ & $\begin{array}{l}\text { \%/week } \\
\text { June }\end{array}$ & $\begin{array}{l}\text { \%/week } \\
\text { July }\end{array}$ & $\begin{array}{l}\text { \%/week } \\
\text { August }\end{array}$ & Average \% \\
\hline MCT & 67.29 & 66.86 & 66.17 & 66.88 & 67.21 & 67.26 & $66.95 \pm 0.34$ \\
C1 & 5.61 & 5.27 & 5.64 & 6.63 & 6.7 & 6.29 & $6.02 \pm 0.48$ \\
C2 & 4.13 & 4.68 & 5.69 & 4.90 & 5.43 & 6.82 & $5.27 \pm 0.75$ \\
C3 & 5.4 & 5.34 & 5.31 & 4.90 & 5.23 & 5.43 & $5.29 \pm 0.15$ \\
C4 & 4.56 & 4.97 & 6.19 & 5.44 & 4.57 & 4.26 & $4.99 \pm 0.57$ \\
C5 & 1.77 & 1.46 & 0.87 & 0.86 & 1.14 & 1.99 & $1.35 \pm 0.38$ \\
C6 & 4.43 & 4.09 & 3.49 & 4.32 & 2.57 & 2.84 & $3.62 \pm 0.63$ \\
C7 & 1.18 & 1.17 & 0.87 & 0.86 & 0.86 & 2.56 & $1.12 \pm 0.53$ \\
C8 & 1.18 & 1.46 & 1.45 & 1.15 & 1.14 & 0.57 & $1.16 \pm 0.26$ \\
Other companies & 4.43 & 4.68 & 4.36 & 4.04 & 5.14 & 1.99 & $4.11 \pm 0.88$ \\
TOTAL & 100 & 100 & 100 & 100 & 100 & 100 & 100 \\
\hline
\end{tabular}

$33.05 \%$ company $\mathrm{C} 1$ contributes $6.02 \% \pm 0.48 \%, \mathrm{C} 2$ $5.27 \% \pm 0.75 \%$, C3 $5.29 \% \pm 0.53 \%$, and C4 4.99\% \pm $0.57 \%$ with the other companies taking the remainder.

\subsection{Waste Characterization}

Municipal solid wastes characterized in these data tables came from residential, commercial, institutional, or industrial sources. After sampling, sorting and weighing the waste generated within Thika municipality was characterized as shown in Fig. 4.

From Fig. 4, sixty eight percent (68\%) the waste came primarily from four components; paper, plastic, organics and food. Food accounted for $15.51 \% \pm$ $0.95 \%$, paper $18.31 \% \pm 1.7 \%$, plastics $17.89 \% \pm$ $0.81 \%$ and organics $16.51 \% \pm 1.01 \%$, respectively obtained at $95 \%$ confidence level. This result compare well with the findings of K. Singh et al. [7] on Municipal Solid Waste to Energy Potential for Application in Trinidad and Tobago work which indicated that Sixty eight percent $(68 \%)$ of household waste came from primarily four components: paper, plastic, organics and food. Food accounted for $21 \%$, paper $19 \%$, plastics $17 \%$ and organics $11 \%$, respectively. Also Matthew Chester et al. [8] in their work on comparison of the physical and chemical composition of UK waste streams based on hypothetical compound structure noted that paper accounted for $16.28 \%$, kitchen waste $25.98 \%$, garden waste $10.18 \%$ and textile at $3.18 \%$. Each of the components has some level of recovery. The opinion of subject matter 


\section{Thika municipality waste characterization}
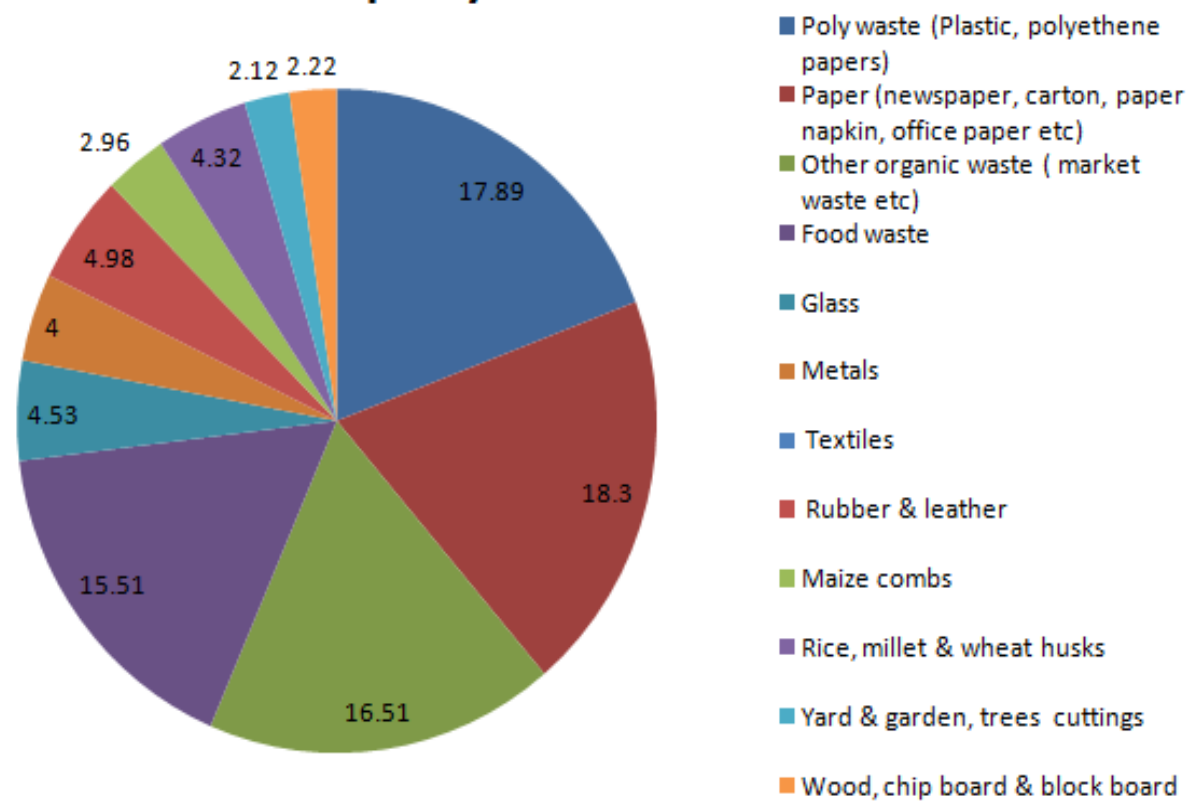

Fig. 4 Thika municipality waste characterization.

salvagers interviewed at the dumpsite anticipated possible high recovery rates. The highest recovery rate is on food waste because of the existing arrangement between salvagers of the food waste and local people who buy these food wastes for pig rearing. Another recovered waste is plastic (soft plastic) which is sold to recyclers to be recycled for manufacture of plastic products. Recovery of materials for recycling and composting was estimated at 10.21 tonnes or $11.35 \%$ of daily generation, leaving 76.44 tonnes per day which can be converted into useful energy.

\section{Conclusion}

Due to industrial and population growth in Thika Municipality waste generation has been increasing, which poses a challenge to the policy makers on how to address the issue of waste generated. It's therefore important for the County government to have the right information on how to address the problems of MSW in Thika Municipality in Kiambu County. From the statistical data analyzed, waste generated per day stands at approximately 86.15 tonnes or $0.412 \mathrm{~kg}$ per person per day, translating to about 31,629 tonnes of waste annually which is the waste dumped at
Kang'oki dumpsite in Thika. This waste has a lot of energy potential if appropriate Waste to Energy (WTE) technologies is used. WTE is a proven, environmentally sound process that provides reliable electricity generation and has been extensively used in Europe and other developed nations including Asia [8]. MSW is a good source of energy but this depends upon the moisture and energy content of waste material [2]. It has been established that thermal treatment of MSW results in the generation of about 500 to $600 \mathrm{KWh}$ of electricity per ton of MSW combusted [7]. Although such WTE process may cost high initially, economical, social and environmental benefits exceed such costs and essentially reduce the country's carbon footprint. WTE technologies can be used to address the problems of waste management in Thika. Therefore, WTE technologies offer a good solution for waste management not only within Thika municipality but also other towns in Kenya where waste management is a major challenge.

\section{References}

[1] American Society of Mechanical Engineers. 2014. "Waste to Energy, Summary Report." Accessed July 5, 


\section{Municipality of Kiambu County, Kenya}

2014. http//www.asme.org.

[2] Kumar. S. J., Subbaiah. K. V., and Rao. P. V. V. 2010. "Waste to Energy-A Case Study of Eluru City, Andhra Pradesh International." Journal of Environmental Sciences 1 (2): 26-28.

[3] Qdais, H. A. A., Hamoda M. F., and Newham J. 1997. "Waste Management \& Research." Accessed May 10, 2014. http//www.sagepub.com/home.nav.

[4] Smith, F. L. 1975. A Solid Waste Estimation Procedure: Material Flows Approach. U.S.: Environmental Protection Agency (SW-147).

[5] Mirakovski, D., Hadzi-Nikolov, M., Despodov, Z., Doneva, N., and Mijalkovski, S. 2011. "Characterization of Solid Waste.” Journal of Environmental Sciences 2 (2): 16-21.

[6] Darnay, A., and W. E. Franklin. 1977. The Role of
Packaging in Solid Waste Management, 1966 to 1976. U.S.: Public Health Service Publication, Government Printing Office.

[7] Kamel Singh, Solange O. Kelly and Musti K. S. Sastry. 2009. "Municipal Solid Waste to Energy Potential for Application in Trinidad and Tobago." The Journal of the Association of Professional Engineers of Trinidad and Tobago 38 (1): 42-49.

[8] Chester, M., Stupples, D., and Lees, M. 2008. "Comparison of the Physical and Chemical Composition of UK Waste Streams Based on Hypothetical Compound Structure." In 13th European Biosolids and Organic Resources Conference, 10-12.

[9] Franklin Associates, Ltd. 1988. Characterization of Municipal Solid Waste in the United States, 1960 to 2000 (Update 1988). U.S.: Environmental Protection Agency. 